\title{
Food resource matching by foraging tits Parus spp. during spring-summer in a Mediterranean mixed forest; evidence for an ideal free distribution
}

\author{
MARIO DÍAZ ${ }^{1 *}$, JUAN CARLOS ILLERA ${ }^{2} \&$ JUAN CARLOS ATIENZA ${ }^{3}$ \\ ${ }^{1}$ Departamento de Biología Animal I (Vertebrados), Facultad de Biología, Universidad Complutense, \\ E-28040 Madrid, Spain \\ ${ }^{2}$ c/Seseña, 31, E-28024 Madrid, Spain \\ ${ }^{3}$ Departamento de Biología Animal I (Entomología), Facultad de Biología, Universidad Complutense, \\ E-28040 Madrid, Spain
}

\begin{abstract}
We analysed whether patterns of microhabitat use by Blue Tits Parus caeruleus, Great Tits Parus major and Crested Tits Parus cristatus inhabiting a mixed forest consistently matched the patterns of food availability experienced by foraging birds during spring-summer. The use of five microhabitats by each bird species (the foliage of three tree species, shrubs and ground) and the availability of food in trees during the prebreeding, breeding and postbreeding periods of the birds' annual cycle were measured. All three tit species foraged mainly in the outer part of tree canopies (small branches and leaves or needles). Tit distributions between tree species matched food resource distributions irrespective of overall food resource levels, which varied four-fold between the study periods, and tit species. Tits also exploited secondary microhabitats (shrubs and ground) in periods of low food availability; Blue Tits tended to use shrubs, whereas Great and Crested Tits foraged on the ground. Between-trees distributions fitted that expected from an ideal free distribution, suggesting that food availability and intraspecific exploitative competition were the main factors governing tree use by tits. In contrast, patterns of use of secondary microhabitats (shrubs and ground) seemed to indicate a role for the species-specific morphological configurations of each tit species since Blue Tits are better adapted to hang and tended to forage in shubs, whereas Great and Crested Tits are better adapted to feed on horizontal surfaces and tended to forage on the ground. No evidence of interspecific interactions was observed. Overall, the results pointed to an independent exploitation of Mediterranean mixed forest by each bird species, food availability and food accessibility being the main factors affecting microhabitat use by foraging tits.
\end{abstract}

The simplest and best known model relating patterns of distribution and abundance of foragers with the distribution of their prey is the ideal free distribution (IFD; Fretwell \& Lucas 1970). This model predicts that individuals should distribute among resource patches so that the proportion of individuals foraging in each patch matches the proportion of food resources provided by such patches (the "input matching" or "habitat matching" rules; Milinski \& Parker 1991). This equilibrium distribution maximizes individual fitness under a given set of assumptions, including a direct relationship between food intake rate and fitness, free settlement of individuals, perfect knowledge of food distributions and no resource depletion (see Milinski \& Parker 1991 and Kacelnik et al. 1992 for reviews).

Further theoretical developments aiming at modifying these rather unrealistic assumptions have shown that food resource

\footnotetext{
* Present address: Departamento de Ecología, Facultad de Biología, Universidad Complutense, E-28040 Madrid, Spain.
}

matching is expected to be the exception rather than the rule. Systematic deviations from food resource matching are expected (1) when factors such as the availability of nest sites or the risk of predation influence fitness together with food (Brown \& Rannala 1995. Moody et al. 1996), (2) when the access of foragers to resource patches is constrained by dominant individuals or by the costs of travelling between patches (Morris 1994, Holmgren 1995, Moody \& Houston 1995. Spencer et al. 1995), (3) when foragers have perceptual limits to assess patch quality (Abrahams 1986, Spencer et al. 1995) or (4) when the metabolic costs of foraging vary among resource patches (Tyler \& Gilliam 1995). Under these conditions, overmatching (i.e. overrepresentation of predators in patches with few prey), undermatching (more predators than expected in patches with large prey availability) or even a lack of a relationship between the proportions of predators and prey among resource patches is expected rather than matching.

In spite of these theoretical results, food resource matching 
has been empirically demonstrated both in field situations and in controlled artificial environments (see Guillemette \& Himmelman 1996 and references therein). These results indicate that the assumptions of the IFD can be fulfilled in natural systems, and it is worthwhile testing whether forager distributions match food resource distributions before attempting to test more elaborate models of predator-prey distribution (Bautista et al. 1995).

Patterns of habitat use by tits (Parus spp.) have been shown to be affected by a variety of factors other than food, such as interspecific competition (Alatalo 1982, Alatalo et al. 1986, Alatalo \& Moreno 1987), intraspecific dominance relationships (Gosler 1987), predation risk (Ekman 1986, Suhonen 1993. Suhonen et al. 1993), foraging costs derived from the ecomorphological configurations of each tit species (Moreno \& Carrascal 1993, Carrascal et al. 1995) and availability of tree holes for nesting (Pulido \& Díaz 1997). However, most of these results have been obtained in situations where food availability was chronically low (e.g. during winter) and/or in habitats which provided little opportunity for spatial segregation of foraging tits (e.g. monospecific pine forests). Further, patterns of food availability among microhabitats rarely have been measured directly, so the possibility of food resource matching by tits, although hardly expected, cannot be considered as disproved by the available evidence.

In this study, we examined whether patterns of microhabitat use by three coexisting tit species inhabiting a Mediterranean mixed forest matched food resource distributions. We compared the patterns of use of primary microhabitats (the foliage of the three tree species composing the forest) by each tit species with patterns of arthropod prey availability among trees, also considering the use of secondary microhabitats (shrubs and ground) by tits. We performed such comparisons in three consecutive study periods in which overall prey availability varied four-fold (Illera \& Atienza 1995). This change in overall food conditions allowed the evaluation of the effects of deviations from IFD assumptions, since the likelihood of such deviations is dependent on food conditions. For instance, interspecific competition and intraspecific dominance (that will produce systematic undermatching of food resources by foragers, the first one especially in the case of subordinate species; Spencer et al. 1995) are most likely at low resource levels, whereas the effects of factors such as predation risk or the availability of nest sites (that tend to produce either overmatching or a lack of relationship between the distributions of foragers and food resources; Brown \& Rannala 1995. Moody et al. 1996) are mainly expected when resource levels are high.

\section{STUDY AREA AND METHODS}

\section{Study area}

Field work was carried out in a c. 850-ha mixed woodland located near San Martín de Valdeiglesias, Madrid province, central Spain $\left(40^{\circ} 19^{\prime} \mathrm{N}, 4^{\circ} 21^{\prime} \mathrm{W}\right.$; c. $650 \mathrm{~m}$ a.s.l.). A mixture of Umbrella Pine Pinus pinea, Holm Oak Quercus ilex and
Prickly Juniper Juniperus oxycedrus composed the tree layer, whereas the shrub layer was dominated by Gum Cistus Cistus ladanifer, French Lavander Lavandula stoechas and Rosemary Rosmarinus officinalis shrubs (Illera \& Atienza 1995). Trees were mixed throughout the study area (all tree species found within a radius of $15.75 \pm 9.56$ (s.d.) $\mathrm{m} ; n=40$ measurements taken from sampling points selected at random) so foraging birds were close to all tree species almost everywhere. This precluded any effects of central-place foraging behaviour of birds (Bautista et al. 1995).

\section{Microhabitat use by tits}

Out of the seven foliage-gleaning bird species inhabiting the study area, we focused our study on three Parus tit species (Blue Tit Parus caeruleus, Great Tit $P$. major and Crested Tit P. cristatus) because (1) they are closely related and show a wide variation in morphology and behaviour (Moreno \& Carrascal 1993), (2) they mainly use tree canopies rather than large branches and trunks (Carrascal \& Tellería 1985) and (3) they were abundant enough to obtain large samples of their foraging behaviour.

We established three sampling periods in relation to the reproductive cycle of the tits: 27 Apri-5 May 1993 (prebreeding period), 30 May-5 June (breeding period) and 2231 August (postbreeding period). The relative use of five microhabitats (ground, shrubs and the canopies of the three tree species) by each tit species was measured by recording the position occupied by birds at 30 -s intervals, taking a maximum of nine samples per individual and never more than three in the same tree (Carrascal 1983). Observations were distributed across the whole study area to sample as many individuals as possible, and they were made only early in the morning (within $3 \mathrm{~h}$ after sunrise) to reduce the effects of the circadian cycles on the microhabitat use showed by tits (Vilà et al. 1996).

\section{Food availability and distribution}

The protocol followed to estimate the availability of arthropods in tree canopies was described by Illera and Atienza (1995). We clipped small branches from randomly chosen trees of each species at each study period after placing them into plastic bags. We then weighed the bagged branches, counted all arthropods ( $>1 \mathrm{~mm}$ ) collected, measured their lengths (appendages excluded) to the nearest $0.1 \mathrm{~mm}$ and estimated their individual dry weights from lengths by means of allometric equations. Arthropod densities were expressed as milligrams per $100 \mathrm{~g}$ of branch, after excluding arthropod groups such as thrips (Thysanoptera), earwigs (Dermaptera) and springtails (Collembola) which are rarely consumed by tits (Cramp \& Perrins 1993).

The volume occupied by the canopies of each tree species was estimated as follows: tree densities were measured at the beginning of the study period in 101 circles of $10-\mathrm{m}$ radius spaced at 50-m intervals along a line chosen arbitrarily. Trees were counted according to species and size 
(three size classes of $0-20,20-40$ and $40-60 \mathrm{~cm}$ diameter at breast height). We estimated the average number of $100-$ $g$ branches contained in randomly selected individual trees belonging to each tree species and size combination. For each tree, we measured the volume occupied by $100 \mathrm{~g}$ of small branches and leaves, and then we estimated how many times this volume was contained in the tree. The figures obtained (Appendix) were assumed to be constant throughout the study period.

Overall levels of resource abundance at each sampling period were estimated by multiplying the mean arthropod densities (in milligrams of dry mass $/ 100 \mathrm{~g}$ of branches) found in each tree species at each sampling period by the vegetation volume (measured as number of 100-g branches/ha) occupied by such tree species.

\section{Data analysis}

The IFD not only predicts that food abundance and forager abundance should be directly related among resource patches but also that the proportions of foragers should match the proportions of resources provided by each resource patch. We tested this prediction of food resource matching by following the procedure developed by Kennedy and Gray (1993). Starting from the "psychological matching law" that relates the individual behavioural allocation between reinforcement sources and the reinforcement ratio of these sources, Kennedy and Gray (1993) concluded that deviations from the food resource matching prediction of the IFD can be detected with precision by testing the fit of a relationship between the log-transformed proportions of food resources in each resource patch (independent variable) and the log-transformed proportions of foragers in such patches (dependent variable) to a linear regression model with a slope of 1 . A slope of $>1$ denotes overmatching of food resources, a slope of $<1$ undermatching and a slope of 0 a lack of relationship between the distributions of foragers and their food supplies (Kennedy \& Gray 1993).

Ideally, we should have tested whether the linear regressions between the log-transformed proportions of arthropods available in each resource patch and the log-transformed proportions of foraging observations in such resource patches had a slope of 1 for each tit species and study period. However, only three data points (three tree species) were available for each tit species in each study period, so such tests could not be performed. To overcome this problem, we calculated regressions between the proportions of individuals of each of the three tit species using each tree species (relative to the total use of trees) and the proportions of arthropods available in such tree species for each study period (these were obviously the same for each bird species). Residuals from these regressions were then analysed by means of one-way ANOVAs with bird species as the classification factor. Significant differences in these residuals would have indicated differences between tit species in their matching of food resources, and such differences would have in- validated our approach of pooling the data for the three bird species for each study period.

Although this procedure allowed us to perform regression analyses, sample sizes remained low ( $n=9$ for each study period), thus reducing the statistical power of significance tests for slopes based on the normal distribution (Sokal \& Rohlf 1981). To increase the power, we tested the statistical significance of our results by means of Monte Carlo simulations, which provide accurate probabilities for null hypotheses concerning slopes on the basis of the databases rather than on any given probability distribution (Montgomery \& Peck 1982). The null hypothesis that there was no relationship between food availability and bird use (slope = 0) was tested by comparing the observed values of slopes with the distribution of values obtained by pairing randomly food availability (X) and bird use $(\mathrm{Y})$ values for each study period. If birds showed food resource matching, then the slope of $\mathrm{Y}$ as a function of $\mathrm{X}$ should be 1 , and $\mathrm{Y}-\mathrm{X}$ values should be independent of the $X$ values (see Manly 1991). We tested such independence (and hence food resource matching) by comparing the observed values of slopes with the distribution of values obtained by pairing randomly $\mathrm{X}$ and $Y$ - X values (Manly 1991). We performed 5000 randomizations in each case, and the intrinsic error of the probability estimates was 1\% (Marriott 1979).

\section{RESULTS}

\section{Microhabitat use}

The average numbers of foraging records per individual bird for the whole study period were $2.32,2.41$ and 1.97 for Blue, Great and Crested Tits, respectively. Most observations on birds looking for food in trees were on small branches $(<1 \mathrm{~cm}$ diameter) and on leaves or needles $(88.8 \%, n=$ 466). This proportion did not differ among tit species $\left(\chi^{2}{ }_{2}\right.$ $=5.97$, n.s.).

All tit species foraged mainly in trees during the breeding period, when overall food availability was greatest (Table 1). Holm Oak was the main feeding tree for Blue and Great Tits and Holm Oak and Umbrella Pine for Crested Tits, whereas Prickly Juniper was scarcely used. This pattern agrees with the general preference for broadleaved trees shown by Blue and Great Tits and for conifers by Crested Tits (Cramp \& Perrins 1993). In periods of lower food availability, tits also foraged in shrubs (especially Blue Tits during the postbreeding period) and on the ground (both Great and Crested Tits in the pre- and postbreeding periods), although the use of these microhabitats was generally less than the use of tree canopies. All these changes were statistically significant, as shown by the fit of log-linear models to the three-way contingency table generated by the factors period.microhabitat'tit species (Sokal \& Rohlf 1981). There were significant differences between tit species in the use of the five microhabitats, as shown by the species $\times$ microhabitat interaction term, and these differences varied be- 
Table 1. Microhabitat use by Blue, Great and Crested Tits and food availability in trees in the three study periods

\begin{tabular}{|c|c|c|c|c|c|}
\hline \multirow[b]{2}{*}{ Study period } & \multicolumn{3}{|c|}{ Microhabitat use } & \multirow[b]{2}{*}{ Arthropod density ${ }^{\mathrm{b}}$} & \multirow{2}{*}{$\begin{array}{l}\text { Arthropod } \\
\text { abundance }\end{array}$} \\
\hline & Blue Tit & Great Tit & Crested Tit & & \\
\hline \multicolumn{6}{|l|}{ Prebreeding } \\
\hline Quercus ilex & 26 & 19 & 18 & $7.54 \pm 1.05$ & 65,030 \\
\hline Pinus pinea & 19 & 10 & 42 & $2.35 \pm 0.43$ & 44,297 \\
\hline Juniperus oxycedrus & 0 & 1 & 5 & $7.04 \pm 2.05$ & 7954 \\
\hline Shrubs & 3 & 3 & 3 & - & - \\
\hline Ground & 1 & 15 & 39 & - & - \\
\hline \multicolumn{6}{|l|}{ Breeding } \\
\hline Quercus ilex & 72 & 48 & 28 & $37.59 \pm 9.95$ & 324,202 \\
\hline Pinus pinea & 8 & 6 & 34 & $6.78 \pm 0.99$ & 127,802 \\
\hline Juniperus oxycedrus & 5 & 6 & 8 & $25.06 \pm 6.44$ & 28,315 \\
\hline Shrubs & 0 & 1 & 1 & - & - \\
\hline Ground & 3 & 5 & 12 & - & - \\
\hline \multicolumn{6}{|l|}{ Postbreeding } \\
\hline Quercus ilex & 44 & 5 & 16 & $8.22 \pm 1.05$ & 70,895 \\
\hline Pinus pinea & 13 & 7 & 15 & $2.56 \pm 0.53$ & 48,255 \\
\hline Juniperus oxycedrus & 0 & 1 & 10 & $6.46 \pm 0.66$ & 7299 \\
\hline Shrubs & 16 & 5 & 7 & - & - \\
\hline Ground & 10 & 22 & 32 & - & - \\
\hline
\end{tabular}

a Number of foraging observations.

${ }^{b}$ Mean ( \pm s.e.) dry mass $(\mathrm{mg})$ of arthropods per $100 \mathrm{~g}$ of branch; $n=10$ trees for each species/study period combination (after lllera \& Atienza 1995).

' Dry mass (mg) of arthropods per ha, computed by multiplying arthropod densities by the average volumes of each tree species (8625. 18,850 and 1130 100-g branches/ha for oak, pine and juniper, respectively; see Appendix). The relative food abundance provided by the tree species in each study period shown in Figure 1 were computed from these figures.

tween study periods, as indicated by the three-way interaction term (Table 2).

\section{Food availability}

Arthropod densities in trees were significantly larger (about four-fold; see Table 1) during the breeding than during the pre- and postbreeding periods. Holm Oak supported significantly larger arthropod densities, followed by Prickly Juniper and finally by Umbrella Pine, in all study periods (details on significance tests can be found in Illera \& Atienza [1995]). The spatio-temporal variations of arthropod biomass were due to differences in the numbers of arthropods between

Table 2. Results of the fit of log-linear models for the three-way contingency table generated by the factors period·microhabitat tit species (Sokal \& Rohlf 1981). The raw data are shown in Table 1

\begin{tabular}{lrrc}
\hline \multicolumn{1}{c}{ Source } & d.f. & \multicolumn{1}{c}{$G^{2}$} & \multicolumn{1}{c}{$P$} \\
\hline Period $\times$ species & 4 & 17.3 & 0.02 \\
Period $\times$ microhabitat & 8 & 110.3 & $<0.001$ \\
Species $\times$ microhabitat & 8 & 119.8 & $<0.001$ \\
Period $\times$ species $\times$ microhabitat & 16 & 30.2 & 0.02 \\
\hline
\end{tabular}

trees and study periods since the mean size of these arthropods did not vary either spatially or temporally (lllera \& Atienza 1995). The greater abundance of Umbrella Pine as compared to Holm Oak and Prickly Juniper in the study area (Appendix) compensated somewhat for the differences in arthropod density among tree species, so most food was provided by the Holm Oak, followed by the Umbrella Pine and finally by Prickly Juniper (Table 1).

\section{Food resource matching and overall food conditions}

The slopes of the regression functions relating the log-transformed proportions of birds foraging in each tree species and the log-transformed proportions of food resources provided by such tree species were significantly different from zero $(P$ $<0.01$ after 5000 Monte Carlo simulations) in every study period (Fig. 1). However, these slopes did not differ from unity in any of the study periods after 5000 simulations, thus indicating food resource matching by foraging tits. The matching of food resources did not differ among tit species for any study period $\left(F_{2.8}=0.67\right.$, n.s.; $F_{2.8}=0.39$, n.s.; $F_{2.8}$ $=1.13$. n.s.; ANOVA of the residuals from the regression functions for the prebreeding, breeding and postbreeding periods according to tit species), thus validating our procedure 


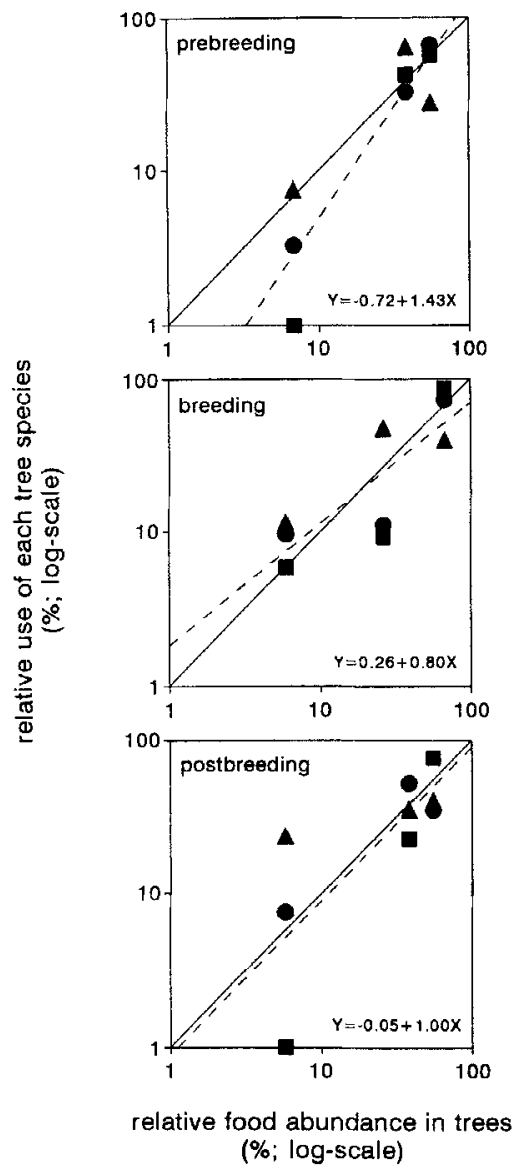

Figure 1. Relationships between the proportion of tits foraging in trees (squares: Blue Tit; circles: Great Tit; triangles: Crested Tit) and the proportion of food resources provided by each tree species (Prickly Juniper, Umbrella Pine and Holm Oak, ordered from left to right along the $\mathrm{X}$-axis) in each study period. The IFD prediction of food resource matching (i.e. a linear relationship with a slope of 1 between the log-proportion of food resources and the log-proportion of foragers among resource patches; see text and Kennedy \& Gray [1993] for further details) is shown by the solid lines crossing each graph, whereas the actual regression functions are shown by dashed lines.

of performing the regression analyses with the data for the three bird species pooled for each study period.

\section{DISCUSSION}

Patterns of use of primary (tree) microhabitats by the three tit species studied matched food resource distributions in spring and summer in spite of dramatic changes in overall food availability. Such changes, which are representative of the dynamics of arthropod populations in both the Mediterranean and other temperate regions (see Herrera 1980, Blondel \& Dias 1994 and references therein), would have produced contrasting food conditions for tits in the study period.
Overall food conditions directly affect the assumptions of the IFD. If food is superabundant relative to the requirements of foraging animals, foragers are expected to concentrate in the best microhabitats, thus overmatching food resources (Pulliam \& Caraco 1984, Brown \& Rannala 1995, Moody \& Houston 1995), or, alternatively, foragers could distribute among microhabitats according to factors other than food availability, such as the availability of nest sites or the risk of predation (Brown \& Rannala 1995, Moody et al. 1996, see Pulido \& Díaz 1997 for a recent example with Blue Tits). As food availability decreases, foragers are expected to expand their use of microhabitats according to their relative food value. In these conditions, habitat matching is expected only if foragers have complete information on patterns of food distribution and they are free to choose among microhabitats (Kacelnik et al. 1992). If food becomes even scarcer, the enhanced effects of processes such as species-specific perceptual limits to ascertain food distributions (Spencer et al. 1995) or competitive asymmetries among individuals (Milinski \& Parker 1991) make habitat matching unlikely. Low levels of food resources also promote interspecific competition (Wiens 1993). Competitive models would allow microhabitat matching only by the dominant species. the subordinate ones being forced to specialize in the use of less-rich microhabitats to avoid competition (Schoener 1982, Morris 1994).

Our unexpected result of close matching irrespective of food conditions strongly suggests that none of the processes outlined above had a major influence on the between-tree species distribution of foraging tits. Rather, patterns of food abundance and distribution and intraspecific exploitative competition for food seemed to be the main factors affecting tree use by any tit species (Milinski \& Parker 1991). Further. no evidence for species segregation within trees was found since all species foraged in the outer parts of tree canopies irrespective of overall levels of food availability. Such segregation has been considered as evidence for competitive interactions between tits species, either alone (Alatalo 1982, Alatalo et al. 1986, Alatalo \& Moreno 1987) or in combination with the risk of predation experienced by foraging birds (Suhonen 1993, Suhonen et al. 1993).

Secondary microhabitats (shrubs and ground) were used mainly during periods of relative food scarcity but were used little when food was plentiful. We could not test directly whether these patterns of microhabitat use also fitted expectations from an IFD since no comparable measures of food availability can be established to sample tree canopies, shrubs and ground. However, the fact that such patterns were species specific and consistent with the ecomorphological configurations of each tit species (Moreno \& Carrascal 1993, Carrascal et al. 1995) pointed to an effect of food accessibility on the patterns of use of these microhabitats by each tit species. Blue Tits are better adapted morphologically to hang from small branches and leaves while Great and Crested Tits are better adapted to stand and feed on horizontal surfaces. Blue Tits tended to forage in shrubs, where hanging is the main foraging posture, whereas Great 
and Crested Tits tended to forage on the ground, where their main foraging posture is upright. These observations suggest that the relative value of shrubs as secondary microhabitats would have been greater than the value of ground for Blue Tits, the reverse being true for Great and Crested Tits. Nevertheless, comparable measures which integrate food abundance with the costs of foraging in trees, shrubs and ground (Brown 1988) are required to test this hypothesis properly.

Our results suggest that the species-specific ideal free responses to food availability and food accessibility could explain the observed patterns of microhabitat use by Mediterranean tit communities during spring-summer. This conclusion is somewhat weakened as compared to tests of IFD models performed in controlled conditions since field conditions make it difficult either to determine accurately whether IFD assumptions hold or to perform meaningful manipulations of food conditions (see Bautista et al. 1995, Milinski et al. 1995, Guillemette \& Himmelman 1996, Petit \& Petit 1996). On the other hand, our work benefited from dramatic changes in the abundance of arthropods in the studied forest. In these conditions, processes dependent on overall levels of food availability should have strongly affected IFD expectations, but we did not find evidence of such changes. Specifically, predictions from models relying on interspecific competition, a process which has been frequently invoked to explain patterns of microhabitat use by tit guilds (reviews by Alatalo 1982, Alatalo et al. 1986, Alatalo \& Moreno 1987, but see Ekman 1986, Suhonen 1993, Suhonen et al. 1993), were not supported in spite of likely conditions of relative food shortage at least during the postbreeding period, when food availability was the lowest and its renewal rate would have been low (Herrera 1980).

We thank G. P. Farinós and J. G. Casanovas for their assistance during field and laboratory work and E. J. Pulido for constructive discussion. Earlier drafts were greatly improved with the invaluable suggestions provided by L. M. Bautista, L. M. Carrascal, J. A. Díaz, E. Moreno and J. L. Tellería. Comments of two anonymous referees also contributed to improve the manuscript during revision. This paper is a contribution to project no. PB-0238 of the Spanish Dirección General de Investigación Cientifica y Técnica (DGICYT).

\section{REFERENCES}

Abrahams, M.V. 1986. Patch choice under perceptual constraints: A cause for departures from an ideal free distribution. Behav. Ecol. Sociobiol. 19: 409-415.

Alatalo, R.V. 1982. Evidence for interspecific competition among European tits Parus spp.: A review. Ann. Zool. Fenn. 19: 309317.

Alatalo, R.V. \& Moreno, J. 1987. Body size, interspecific interactions, and use of foraging sites in tits (Paridae). Ecology 68: 17731777 .

Alatalo, R.V., Gustafsson, L. \& Lundberg, A. 1986. Interspecific competition and niche changes in tits (Parus spp.): Evaluation of nonexperimental data. Am. Nat. 127: 819-834.

Bautista, L.M., Alonso, J.C. \& Alonso. J.A. 1995. A field test of ideal free distribution in flock-feeding Common Cranes. J. Anim. Ecol 64: 747-757.

Blondel. J. \& Dias, P.C. 1994. Summergreenness, evergreenness and life history variation in Mediterranean Blue Tits. In Arianoutsou. M. \& Groves, R.H. (eds) Plant-animal Interactions in Mediterranean-type Ecosystems: 25-36. Dordrecht: Kluwer Academic Publishers.

Brown, C.R. \& Rannala. B. 1995. Colony choice in birds: Models based on temporally invariant site quality. Behav. Ecol. Sociobiol. 36: 221-228.

Brown, J.S. 1988. Patch use as an indicator of habitat preference, predation risk, and competition. Behav. Ecol. Sociobiol. 22: 3747.

Carrascal, L.M. 1983. Análisis comparativo de cinco sistemas de muestreo del uso del espacio en aves forestales. Ardeola 30:4555.

Carrascal, L.M. \& Tellería, J.L. 1985. Estudio multidimensional del uso del espacio en un grupo de aves insectívoras forestales durante el invierno. Ardeola 32: 95-113.

Carrascal, L.M., Moreno, E. \& Mozetich, I. 1995. Ecological plasticity of morphological design: An experimental analysis with tit species. Can. J. Zool. 73: 2005-2009.

Cramp, S. \& Perrins, C.M. (eds). 1993. The Birds of the Western Palearctic, Vol. VII. Oxford: Oxford University Press.

Ekman, J. 1986. Tree use and predator vulnerability of wintering passerines. Ornis Scand. 17: 261-267.

Fretwell, S.D. \& Lucas, H.L. 1970. On territorial behaviour and other factors influencing habitat distribution in birds. Acta Bistheor. 19: $16-36$.

Gosler, A.G. 1987. Pattern and process in the bill morphology of the Great Tit Parus major. Ibis 129: 451-476.

Guillemette, M. \& Himmelman. J.H. 1996. Distribution of wintering Common Eiders over mussel beds: Does the ideal free distribution apply? Oikos $76: 435-442$.

Herrera. C.M. 1980. Composición y estructura de dos comunidades mediterráneas de passeriformes. Doñana Acta Vert. 7: 1-340.

Holmgren, N. 1995. The ideal free distribution of unequal competitors: Predictions from a behaviour-based functional response. I. Anim. Ecol. 64: 197-212.

Illera, J.C. \& Atienza, J.C. 1995. Foraging shifts by the Blue Tit (Parus caeruleus) in relation to arthropod availability in a mixed woodland during the spring-summer period. Ardeola 42: 39-48.

Kacelnik, A., Krebs, J.R. \& Bernstein, C. 1992. The ideal free distributions and predator-prey populations. Trends Ecol. Evol. 7: 50-55.

Kennedy, M. \& Gray, R.D. 1993. Can ecological theory predict the distribution of foraging animals? A critical analysis of experiments on the ideal free distribution. Oikos 68: 158-166.

Manly, B.F.J. 1991. Randomization and Monte Carlo Methods in Biology. London: Chapman and Hall.

Marriott, F.H.C. 1979. Bernard's Monte Carlo tests: How many simulations? Appl. Stat. 28: 75-77.

Milinski, M. \& Parker, G.A. 1991. Competition for resources. In Krebs, J.R. \& Davies, N.B. (eds) Behavioural Ecology: An evolutionary approach, 3rd ed.: 137-168. Oxford: Blackwell.

Milinski, M., Boltshauser, P., Büchi, L., Buchwalder, T., Frischknecht, M., Hadermann, T., Künzler, R., Roden, C., Rüetschi, A., Strahm, D. \& Tognola, M. 1995. Competition for food in swans: An experimental test of the truncated phenotype distribution. J. Anim. Ecol. 64: 758-766.

Montgomery, D.C. \& Peck, E.A. 1982. Introduction to Linear Regression Analysis. New York: Wiley \& Sons. 
Moody, A.L. \& Houston, A.I. 1995. Interference and the ideal free distribution. Anim. Behav. 49: 1065-1072.

Moody, A.L., Houston, A.I. \& McNamara, J.M. 1996. Ideal free distributions under predation risk. Behav. Ecol. Sociobiol, 38: 131143.

Moreno, E. \& Carrascal, L.M. 1993. Leg morphology and feeding postures in four Parus species: An experimental ecomorphological approach. Ecology 74: 2037-2044.

Morris, D.W. 1994. Habitat matching: Alternatives and implications to populations and communities. Evol. Ecol. 8: 387-406.

Petit, L.J. \& Petit, D.R. 1996. Factors governing habitat selection by Prothonotary Warblers: Field tests of the Fretwell-Lucas models. Ecol. Monogr. 66: 367-387.

Pulido, F.J. \& Díaz, M. 1997. Linking individual foraging behaviour and population spatial distribution in patchy environments: $A$ lield example with Mediterranean Blue Tits. Oecologia 111: 434442.

Pulliam, H.R. \& Caraco, T. 1984. Living in groups: Is there an optimal group size? In Krebs, J.R. \& Davies, N.B. (eds) Behavioural Ecology: An evolutionary approach, 2nd ed.: 122-147. Oxford: Blackwell.
Schoener, T.W. 1982. The controversy over interspecific competition. Am. Sci. 70: 586-595.

Sokal, R.R. \& Rohlf, F.J. 1981. Biometry. New York: Freeman.

Spencer, H.G., Kennedy, M. \& Gray, R.D. 1995. Patch choice with competitive asymmetries and perceptual limits: The importance of history. Anim. Behav. 50: 497-508.

Suhonen. J. 1993. Predation risk influences the use of foraging sites by tits. Ecology 74: 1197-1203.

Suhonen, J., Halonen, M. \& Mappes, T. 1993. Predation risk and the organization of the Parus guild. Otkos 66: 94-100.

Tyler, J.A. \& Gilliam, J.F. 1995. Ideal free distributions of stream fish: A model and test with minnows, Rhinicthys atratulus. Ecology 76: 580-592.

Vilà, C., Rodríguez-Teijeiro, J.D. \& Oliva, F. 1996. Diurnal cycles in microhabitat use by forest passerines: Consequences for community structure. Ibis $138: 308-314$

Wiens, J.A. 1993. Fat times, lean times and competition among predators. Trends Ecol. Evol. 8: 348-349.

Submitted 27 May 1997; revision accepted 4 August 1997

\section{APPENDIX}

Tree densities and volumes in the study area

\begin{tabular}{|c|c|c|c|}
\hline & Pinus pinea & Quercus ilex & Juniperus oxycedrus \\
\hline Tree abundance (no./ha \pm s.e.) ${ }^{\mathrm{a}}$ & $58.3 \pm 7.6$ & $31.8 \pm 3.9$ & $12.6 \pm 2.6$ \\
\hline \multicolumn{4}{|l|}{ Tree size distribution $(\%)$} \\
\hline $\begin{array}{l}\text { 0-20 cm d.b.h. } \\
20-40 \mathrm{~cm} \text { d.b.h. } \\
40-60 \mathrm{~cm} \text { d.b.h. }\end{array}$ & 43.78 & $\begin{array}{l}70.30 \\
40.00\end{array}$ & $\begin{array}{r}100.00 \\
29.70 \\
16.20\end{array}$ \\
\hline \multicolumn{4}{|l|}{ Tree size (no, 100-g branches \pm s.e.) ${ }^{\mathrm{b}}$} \\
\hline $\begin{array}{l}0-20 \mathrm{~cm} \mathrm{d.b.h.} \\
20-40 \mathrm{~cm} \mathrm{d.b.h.} \\
40-60 \mathrm{~cm} \mathrm{d.b.h.}\end{array}$ & $136 \pm 26$ & $\begin{array}{l}141 \pm 37 \\
378 \pm 48\end{array}$ & $\begin{aligned} 90 & \pm 11 \\
578 & \pm 165 \\
692 & \pm 141\end{aligned}$ \\
\hline Vegetation volume (no. 100-g branches/ha) & 18,850 & 8625 & 1130 \\
\hline
\end{tabular}

${ }^{a} n=101$ plots of $10-\mathrm{m}$ radius.

${ }^{\mathrm{b}} n=10$ trees per species-size combination, except for I. oxycedrus, where 15 trees were measured. 